Article

\title{
Review and New Evidence on the Molluscan Purple Pigment Used in the Early Late Bronze Age Aegean Wall Paintings
}

\author{
Sophia Sotiropoulou 1,*(D), Ioannis Karapanagiotis ${ }^{2}(0)$, Konstantinos S. Andrikopoulos ${ }^{3}\left(\mathbb{D}\right.$, Toula Marketou ${ }^{4}$, \\ Kiki Birtacha ${ }^{5}$ and Marisa Marthari ${ }^{6}$ \\ 1 Foundation for Research and Technology-Hellas, Institute of Electronic Structure and Laser (FORTH-IESL), \\ N.Plastira 100, 70013 Vassilika Vouton, Crete, Greece \\ 2 University Ecclesiastical Academy of Thessaloniki, 54250 Thessaloniki, Greece; y.karapanagiotis@aeath.gr \\ 3 Department of Physics, University of Patras, 26504 Rion, Greece; kandriko@upatras.gr \\ 4 Ministry of Culture, 22nd Ephorate of Prehistoric and Classical Antiquities, Ippoton Street, 85100 Rhodes, \\ Greece; kbepka@yahoo.gr \\ 5 The Archaeological Society at Athens, Excavations at Akrotiri, Thera, Tholou 10, 10556 Athens, Greece; \\ kikibir@otenet.gr \\ 6 Ministry of Culture, 21st Ephorate of Prehistoric and Classical Antiquities, Epameinonda St., 10555 Athens, \\ Greece; mmarthari@gmail.com \\ * Correspondence: sophiaso@iesl.forth.gr
}

check for updates

Citation: Sotiropoulou, S.; Karapanagiotis, I.; Andrikopoulos, K.S.; Marketou, T.; Birtacha, K.; Marthari, M. Review and New Evidence on the Molluscan Purple Pigment Used in the Early Late Bronze Age Aegean Wall Paintings. Heritage 2021, 4, 171-187. https:// doi.org/10.3390/heritage4010010

Received: 19 December 2020 Accepted: 11 January 2021 Published: 14 January 2021

Publisher's Note: MDPI stays neutral with regard to jurisdictional clai$\mathrm{ms}$ in published maps and institutional affiliations.

Copyright: (C) 2021 by the authors. Licensee MDPI, Basel, Switzerland. This article is an open access article distributed under the terms and conditions of the Creative Commons Attribution (CC BY) license (https:// creativecommons.org/licenses/by/ $4.0 /)$.

\begin{abstract}
The production and use of the pigment extracted from the murex molluscs is discussed here in association with the purple textile dyeing industry in the Prehistoric Aegean. "True" purple has been identified in a number of archaeological finds dating from the early Late Bronze Age, found in old and recent excavations at three different but contemporary sites: Akrotiri and Raos on Thera, and Trianda on Rhodes. The chemical composition of the shellfish purple pigment either found in lump form or applied on wall paintings is discussed in relation to the archaeological context of several examined finds and with reference to Pliny's purpurissum. The results of a comprehensive methodology combining new data obtained with molecular spectroscopies (microRaman and FTIR) and already reported data obtained with high performance liquid chromatography coupled with a diode array detector (HPLC-DAD) applied to samples of the murex purple finds are discussed in comparison to published data relating to few other instances of analytically proven murex purple pigment found in the Aegean over the timespan of its documented exploitation.
\end{abstract}

Keywords: Late Cycladic I; brominated indigoids; Muricidae; murex; purpurissum; true purple; microRaman; FTIR; HPLC-DAD

\section{Introduction}

The exploitation of molluscs providing the fabulous purple dye (in Greek, porphyra = $\pi \circ \rho \phi v \hat{v} \alpha)$ in the Prehistoric Aegean, as evidenced by archaeological research, illuminates many aspects of the societies that developed it and bequeathed it to subsequent civilizations. The production at a commercial scale of "true purple" dye, obtained from the secretions of shellfish species native to the Mediterranean Sea, had a significant social and economic impact in the Aegean Bronze Age. Dyeing seems to have been an integral part of the production and distribution of textiles, whereas the extraction and the application process of the purple dye, demanding exceptional skills and much know-how, was presumably a preserved secret among the guild of specialized experts. The impact of the murex dye industry in the ancient Mediterranean societies was related to the value of dyed garments and colored textiles in general as symbols of social status and power, with the shellfish purple dye representing an added value and denoting the highest societal rank in many cultures around the Mediterranean basin during the Bronze Age and far later on [1,2].

Although the earliest record for the purple dye comes from inscriptions on the Mycenaean Linear B clay tablets dating to the 13th century BC, where the term "royal purple" 
(Knossos X 976) was probably mentioned for the first time [3], important shell deposits of gastropods of the Muricidae family have been studied and confidently attributed to a non-dietary use of molluscs far earlier. Heavily fragmented shell debris in a primary production context or concentrations of crushed murex in a secondary use context are considered evidence of purple dye production activity at many Aegean sites, dating mainly from the Middle and Late Minoan periods, and in certain cases from the Early Minoan period [4]. The early archaeological evidence of the purple industry around the Mediterranean Basin is significant in both the Aegean and the Levantine littoral [4-9]. The question of whether the secret of the purple dyeing process and its exceptional properties was first discovered in the Aegean or the Levant has yet to be resolved, but given the established trading relations between the Aegean and the eastern Mediterranean coasts in the middle of the second millennium $\mathrm{BC}$, it is reasonable to suggest that the process of extracting a commercial dye from murex species may have been practiced contemporaneously in many of the important Eastern Mediterranean centers, where familiarity with marine molluscs is evidenced by the shell middens, as well as by shells found in second uses (mortar, etc.) [10].

The chances of finding the proper product of the purple dyeing industry, a purpledyed textile, decrease geometrically as we go back in time. However, residues of dyed textile, in which mollusc purple is identified, date back to the Late Bronze Age. In present evidence, the earliest cases belong to archaeological sites in Syria. Purple-dyed textile fragments were found first in a royal tomb complex in the Bronze Age palace of ancient Qatna, Tell Mishrife, Syria, discovered during excavations in 2002 [11]. It is estimated that the tomb was used for 300-400 years for the burial of kings, prior to the destruction of the palace by the invading Hittites in $1340 \mathrm{BC}$, a date that is extremely early given the fragility of the fiber substrate. Brominated and non-brominated indigoid compounds of a similar composition were identified in purple-colored extracts both from fragments of woven fabrics and samples in brown-stained areas of the layer of sediment covering the tomb floor, from which it was concluded that the colorants present in the sediment extracts were residues of the purple used to dye the royal fabrics [12]. Then, in a more recent excavation, shellfish purple-dyed textile residues dating to the 18th-16th century BC were identified in Chagar Bazar [13]. This earliest direct evidence of purple-dyed textiles confirm the early dating of the purple-dyeing industries at the coastal Levantine sites in Syria (Minet el-Beidha/Ras Shamra) and in Lebanon (Sarepta), so far documented only through the studied heaps of murex, as well as the identified purple substances on shreds of jar-type vessels with purple sediment in their interiors [7,10,14-17].

Another direct piece of evidence for the shellfish-purple dyeing industry raised from an excavated complex alluding to a dyeing installation is provided by containers that preserve purple traces, analytically proven to contain indigoid compounds $[1,18]$. One of the earliest instances of such purple-stained vessels with crushed shells, which dates back to the Middle Minoan period, MM IIB, was found at the site of Pefka, near Pacheia Ammos, on Crete $[19,20]$.

A third, equally strong direct piece of evidence for purple production is the identification of the pigment prepared for use in painting; we are referring to the purpurissum, according to Pliny the Elder and his vat-dyeing recipe [21]. The murex purple dyestuff in the form of pigment with a calcium carbonate base and its application in painting was first identified and fully characterized in the context of the Xeste 3 wall paintings at Akrotiri on Thera [22-24], referring in fact to Pliny's vat-dyeing recipe for purpurissum.

Over the past 30 years, deep insights have been given into the production of murex purple, its coloring and medicinal properties, and the technology of its application, as a result of research findings in various disciplines [17,25-30]. The recent literature on the investigation of the chemical composition of purple, either dye or pigment, identified in archeological contexts, as well as on the factors that may affect and differentiate the color at all stages of production and the dyeing process, is extensive and yet far from being exhaustive [31,32]. 
This paper comparatively examines the results of the analysis of samples from three archaeological finds of the purple pigment in lump form, coming from the excavations of Akrotiri on Thera and Trianda on Rhodes, as well as of a representative sample from a purple paint detail on a wall painting at the recently excavated (2009-2012) Raos site, Thera, in which the valuable pigment was used. The chemical composition of the purple pigments and paints dating from the early Late Bronze Age ( 17th century BC or earlier), identified at the three contemporary Aegean sites (Akrotiri and Raos on Thera, and Trianda on Rhodes), is discussed with reference to the archaeological context of the unique finds. Among the finds discussed, we included the lump of purple pigment found in Akrotiri, Complex D, room 12 (AKR-10891), which was the starting point and the motivation for the development of a comprehensive methodology that allows us today not only to recognize the nature the organic colorant but also to determine its exact composition in chromophores, as well as to identify the inorganic material base that makes it a pigment for painting on different substrates. Therefore, the methodology that has been progressively developed over the last 20 years and applied case-by-case to finds that came to light at different times is applied here in order to discuss the results for a set of samples that makes sense to study comparatively. New spectroscopic results, through microRaman and FTIR techniques applied on the investigated purple pigments and a purple wall painting detail, follow through previous data obtained on other true purple samples [23,24]. The spectroscopic data are combined with previously reported chromatographic studies of samples taken from the same archaeological finds to achieve their complete characterization [30]. The data collected with high performance liquid chromatography coupled with a diode array detector (HPLC-DAD) are presented here in detail and are interpreted, along with the spectroscopic results, with a fresh view from an interdisciplinary angle on the basis of new findings, allowing better understanding and interpretation of the results relating to their different excavation context as they come from different proper archaeological sites, which are, however, contemporary and belong to the same geopolitical context of the Late Bronze Age I in the Aegean.

\section{Materials and Methods}

2.1. The Archaeological Samples under Investigation

2.1.1. Samples Taken from Three Finds of Purple Pigment Excavated in Lump Form

- AKR-10891: A sample from a lump of purple pigment found in the Late Cycladic I/Late Minoan IA city at Akrotiri, Thera, in Complex D, room 12. A first non-invasive investigation of this pigment with X-ray fluorescence spectrometry was reported in [33]. A microsample taken from the same find with inv. no. 10891 was investigated in the past using microRaman, FTIR, and HPLC techniques and compared with samples taken from purple paint details in the wall paintings of Xeste 3, belonging to the iconographic ensemble of the "Saffron Gatherers" and the "Procession of Women with Bouquets" [22-24]. The new sample was analyzed again in the present study and compared with the rest of the samples, and the microRaman and FTIR spectroscopic data are presented here for the first time.

- AKR-10882: A sample from a very small quantity of purple pigment found in the new pillar shaft 53A, during the excavations conducted in the course of construction of the new shelter of the archaeological site at Akrotiri.

- TRI-PR 13: A sample from a quantity of purple pigment found in the excavation conducted in the Paraskeva plot, in the southwest sector of the Late Bronze Age settlement at Trianda (Ialysos), east of the Trianda stream and the modern street above it.

\subsubsection{Microsample Taken from the Wall Painting Excavated at Raos, Thera}

- RAOS-KAL1. A microsample taken from a rosette purple detail on a wall-painting fragment from the excavated site of Raos, Thera. The site of Raos is located on the south side of the caldera, with an excellent view of the Kamenes islets, Therasia, and 
north Thera. A tiny portion of the sample was embedded in epoxy resin (Struers CaldoFix-2) and prepared in a polished cross-section to be studied with microRaman spectroscopy. The rest of the sample was used for HPLC analysis, first reported in [30] and interpreted comparatively in this work, along with the microRaman spectroscopic results, presented here for the first time.

\subsection{MicroRaman Spectroscopy Experimental Details}

Analyses focusing, under microscope, on the purple particles were made with a Horiba Jobin-Yvon HR800 dispersive Raman spectrometer equipped with Edge filters and using the $458 \mathrm{~nm}$ excitation wavelength of an air-cooled (Melles Griot) $\mathrm{Ar}^{+}$laser. Laser power at the sample was settled on $100 \mu \mathrm{W}$ in order to preserve the sample integrity. Sample visualization and Raman scattering collection were performed through a reverse microscope notably equipped with a $100 \times$ objective, which allows a spatial resolution close to $1 \mu \mathrm{m}$ (Note: In the ideal case the spot is $\sim 0.5 \mu \mathrm{m}$-the diffraction limit). The 600 groves $/ \mathrm{mm}$ grating used gives a spectral resolution of about $3 \mathrm{~cm}^{-1}$ for the signal recorded with an air-cooled CCD detector. The spectra presented were baseline corrected to remove the intense fluorescence contribution exhibited by the measured materials.

\subsection{FTIR Spectroscopy Experimental Details}

A Biorad FTS 175 system was employed for the acquisition of the FTIR spectra covering the wavenumber range of $4000-400 \mathrm{~cm}^{-1}$. A few particles $(\sim 1 \mathrm{mg})$ from each of the raw pigment samples were set aside and mixed with anhydrous $\mathrm{KBr}$ and then pressed into pellets. The spectra were collected in transmission mode and converted to absorbance mode with a spectral resolution of $4 \mathrm{~cm}^{-1}$ representing an average of 64 scans.

\subsection{HPLC-DAD Experimental Details}

Samples were treated with hot dimethyl sulfoxide (DMSO) to extract and solubilize the colorants [30]. The HPLC-DAD system (Thermoquest, Manchester, UK) consisted of a 4000 quaternary HPLC pump, a SCM 3000 vacuum degasser, an AS3000 auto sampler with column oven, a Rheodyne 7725i Injector with $20 \mu \mathrm{L}$ sample loop, and a Diode Array Detector UV 6000LP. The HPLC was operated using (A) water $+0.1 \%(v / v)$ trifluoroacetic acid and (B) acetonitrile $+0.1 \%(v / v)$ trifluoroacetic acid [30]. Separation was achieved with an Altima C18 (Alltech Associates Inc., Chicago, IL, USA) column (5 $\mu \mathrm{m}$ particle size, $250 \mathrm{~mm} \times 3.0 \mathrm{~mm}$ ) at a stable temperature of $35{ }^{\circ} \mathrm{C}$ using the following gradient elution [30]: 0-0.5 min: 50\% B isocratic; 0.5-12 min: linear gradient to $60 \% \mathrm{~B} ; 12-12.5 \mathrm{~min}$ $60 \%$ B isocratic; $12.5-14$ min linear gradient to $70 \%$ B; 14-17 min linear gradient to $85 \%$ B; $17-18 \mathrm{~min} 85 \% \mathrm{~B}$ isocratic; and 18-21 min linear gradient to $100 \% \mathrm{~B}$. The amounts of the analyzed samples were in the order of $0.5 \mathrm{mg}$.

\section{The Archaeological Context of the Finds under Investigation}

\subsection{The Purple Pigment Finds from Akrotiri, Thera}

Two lumps of purple pigment, found free of any support or container in rooms of different buildings in the city, were identified as having a similar physical appearance.

The first lump (inv. no. 10891), with a volume of about $20 \mathrm{~cm}^{3}$, was found in (Building Complex Delta, Romford, UK) room 12. We assume that the color was stored not in powder form after any treatment such as grinding, but rather in raw form, as a cohesive mass, because following its excavation and storage in a glass container for over 30 years it was still cohesive. The quantity, form, and context indicate that it was not an accidental find in the field.

We do not know if it was kept in a vessel or other container of perishable material (bag from plant fibers, basket, etc.). A triton shell was found next to the lump of purple. Particularly interesting is the fact that from the same place came a large amount of yellow ochre, which weighed about $8 \mathrm{~kg}$ and was probably stored in a large pithos [34]. The pithos was found lying next to the triton and the purple pigment. The presence in the same room 
of two lumps of pigments-the purple, which is valuable and rare, and the ochre, which is common but here in such great quantity-is extremely important. The pigments were kept there, probably to be distributed subsequently to artists and artisans.

The dimensions of the second purple find (inv. no. 10882) were comparably smaller (Figure 1). It was found in a closed area during the excavation of pillar shaft 53a for the new shelter of the excavation site. Pillar shaft 53a is located to the west of Xeste 3 . The lump of pigment was very small and could have been an accidental find derived from the destruction layer. However, the finding in the same place of a clay vase containing dissolved masses of impure red ochre suggests that perhaps the purple pigment was kept there intentionally.
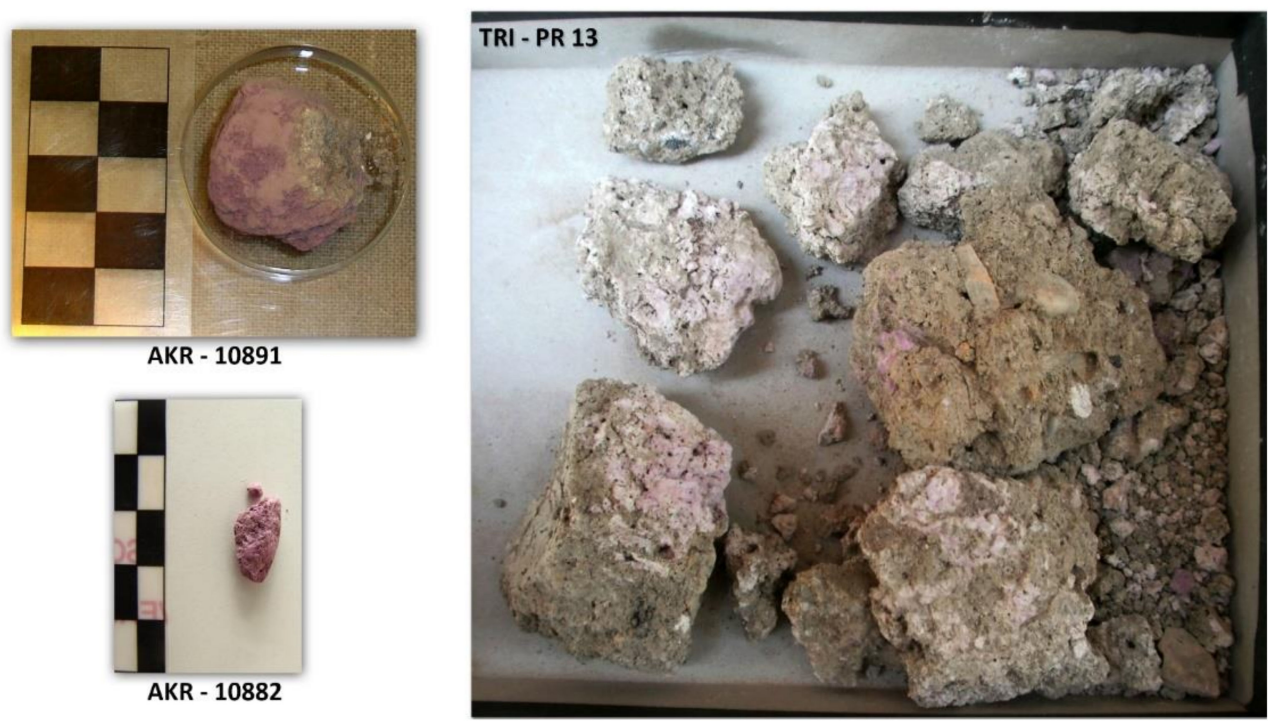

Figure 1. Photographs of the three purple pigment finds AKR-10891, AKR-10882, and TRI-PR13. (The photograph of pigment inv. no 10891 is of the part exhibited in the Museum of Prehistoric Thera, Thera, Greece).

\subsection{The Purple Pigment Find from Trianda, Rhodes}

A mass of purple pigment (TRI-PR13) was found at a depth of $3.40 \mathrm{~m}$ below the present surface in a layer of debris discarded in the northeast open space outside the monumental building located north of an E-W street crossing the southern zone of the prosperous Late Bronze Age IA city at Trianda [35]. The building (partially revealed in max. dimensions: $16.10 \times 13.80 \mathrm{~m}$ ) is a Xeste (of ashlar masonry), similar to the Xestai at Akrotiri, Thera $[35,36]$. The pigment was recovered from the earth filling of the debris bordering the west facade of the Xeste, partly covered with tephra from the Thera eruption. It was found just beneath a small fresco fragment (APX 2098) [37] depicting an elaborate black running spiral on a shiny whitish surface, among other fragmentary monochrome, polished dark grey, reddish, orange, or whitish frescoes; pieces of round tripod offering tables made of lime plaster; a reddish schist slab; and fragments of conical or some semiglobular cups and painted Late Bronze Age IA pottery, as well as animal teeth and bones. The pigment had the appearance of a cohesive dry mass, most probably once kept in a container of perishable material (see Figure 1).

The context comprised a secondary deposition of several materials fallen among the pre-eruption earthquake ruins, which were moved to outside the ruined building in order to clean it and prepare for its reconstruction. Similar contexts appear very often in the Late Bronze Age IA layers, mostly outside buildings, and they are indicative of the intensive cleaning activities of the earthquake ruins at Trianda before the tephra fall [36] (pp. 84-85), [38] (pp. 31-32), [39] (pp. 103-104, 107, 109). The excavation in the Paraskeva plot yielded abundant evidence of such intensive activities, since the exterior areas of the Xeste north of the E-W street was covered almost entirely with such secondary depositions 
containing many important materials [36] (pp. 83-85) and provided strong contextual evidence for the explanation of several aspects of the settlement and the activities of the people.

\subsection{Purple Paint Details on a Wall Painting Excavated at Raos, Thera}

The excavations at Raos brought to light a significant Late Cycladic I/Late Minoan IA complex atop a long crest consisting of a building surrounded by a spacious courtyard bounded by a robust stone-built enclosure wall [40-42]. Despite the poor state of preservation by Theran standards, the evidence shows that the Raos "villa" would have been quite impressive, with an upper story, high-quality wall paintings, and rather luxurious household equipment. It was situated on the outskirts of the Late Cycladic I/Late Minoan IA city at Akrotiri, less than $1 \mathrm{~km}$ from its northwest limit, on the natural land route leading from the coast to the hinterland of the Akrotiri Peninsula, where there are extensive tracts of arable land.

The fresco fragment from which the sample was taken derived from the north part of the southeast wing of the Raos residential building. It belonged to a heap of fresco fragments recovered on the floor of the ground floor. The heap covered an area of approximately $2 \mathrm{~m}^{2}$. Most of the fresco fragments were found on entire or broken mud bricks and must have come from a collapsed mud-brick wall.

Near the heap of fresco fragments, two dressed tuff bases of a pier-and-door partition were found in situ. The evidence shows that a pier-and-door partition provided access to the southeast wing via a paved corridor at the heart of the building. Almost no moveable finds, neither in situ nor fallen from an upper story, were excavated in the north part of the southeast wing, i.e., in the space where the wall paintings were found. The exact plan and arrangement of the wing is difficult to grasp because of its almost complete destruction. However, both the particular architectural features (pier-and-door partition, frescoed mud-brick wall) and the absence of moveable finds indicate that this area was possibly used for rituals or formal receptions.

All the fresco fragments belonged to one composition, which we called the "Wall Painting with the Rosettes and Lilies." This is tripartite in structure. An upper narrow frieze of polychrome rosettes, some of which have purple petals, crowns a wide middle zone (Figure 2). In this main zone, pendent red triangular surfaces alternate with upright triangles, covered with scattered red lily flowers on a white ground. A lower zone of oblong panels embellished with colored wavy bands imitates a polychrome veined marble dado [41] (pp. 212-213), [42] (pp. 137-139).

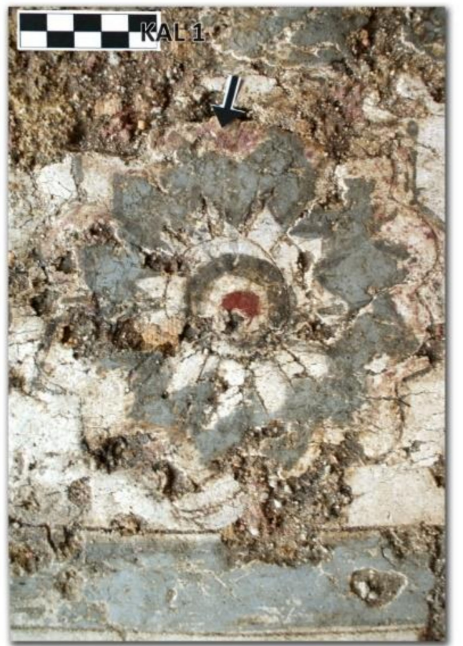

(a)

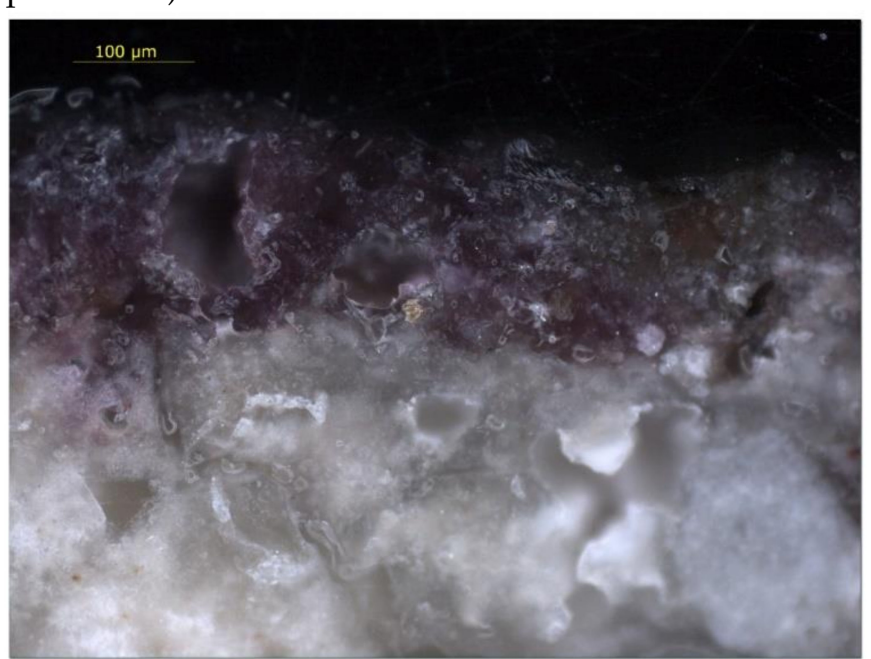

(b)

Figure 2. (a) Photograph of the wall-painting detail from Raos, with an indication of the sampling site on the purple petal of the rosette and (b) microphotograph of the cross-section of sample RAOS-KAL1. 


\section{Analytical Results and Discussion}

\subsection{Identification of the Brominated Indigoid Chromophores in the Purple Pigment}

microRaman spectra were acquired in all the examined archaeological purple samples, on grains set aside from the three finds of purple pigment lumps (AKR-10882, AKR-10891, and TRI-PR13) and on the microsample from the purple paint detail in the Raos wall painting (RAOS-KAL1) prepared in a polished section, shown in Figure 2. The spectra are presented comparatively in (Figure 3); they present a perfect match of their peaks in both position and relative intensity for most of the characteristic vibrational bands of $6,6^{\prime}$-dibromoindigotin (DBI), the main chromophore compound of murex purple. For comparison, the spectrum taken from a reference $6,6^{\prime}$-DBI substance, synthesized according to previously described methods [43], is given in the same graph.

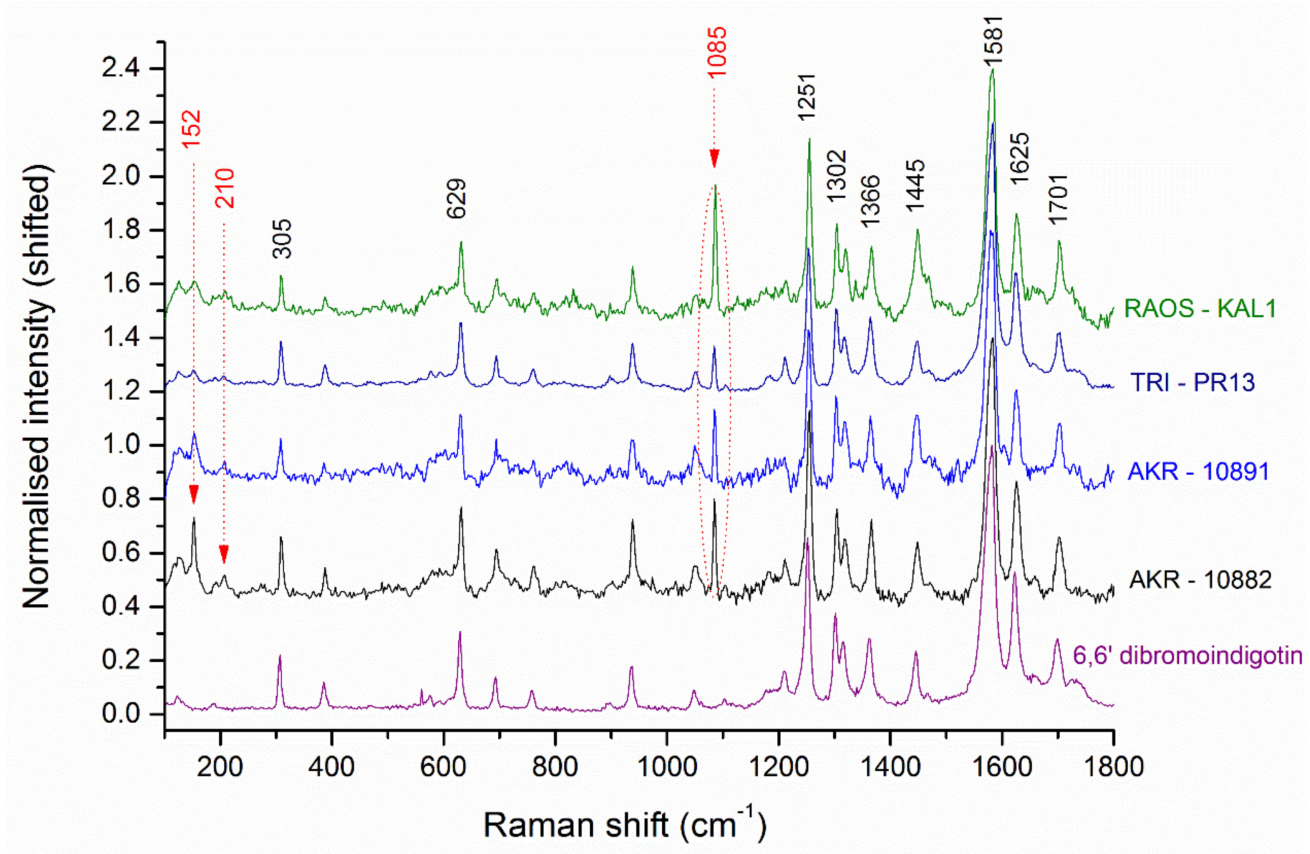

Figure 3. MicroRaman spectra acquired on samples from the purple pigment finds from Akrotiri and Trianda, (AKR-10882, AKR-10891, and TRI-PR13), as well as from the purple paint detail on the wall painting from Raos (RAOS-KAL1). The spectral signature of 6,6'-DBI is displayed in all the spectra acquired on the archaeological samples, shown in comparison with the spectrum taken on a synthetic 6,6'-DBI substance, [43].

The band positions and assignments to the vibrational modes for the $6,6^{\prime}-\mathrm{DBI}$, the main chromophore compound of Tyrian purple, were previously published in comparison with indigo and its corresponding dihalogenated species 6,6'-DXI (where X: I, Br, F, Cl) [44]. A closer look at the spectra of the indigo and the dihalogenated indigoids, comparatively, allows for many similarities to be noticed, which is to be expected given that the majority of the detectable Raman bands are attributed to the indigoid structure. However, the exact position and the relative intensities of the major bands are proper to each halogenated indigoid compound, as the different halogeno-substituents induce differential changes (wavelength shift or relative intensity variance) in the characteristic vibrations that are in common, which makes the Raman spectrum a fingerprint for its identification. The specificity of each Raman spectrum extends even to differentiate two DBI positional isomers, as demonstrated in a recent paper comparing 5,5'-DBI to 6,6'-DBI and showing that the position of the bromine substituents affects many of the key bands of DBI and especially the wavelength position and the relative intensity of the band assigned to the $v(\mathrm{CBr})$ stretching vibration [45]. The $6,6^{\prime}$-DBI in particular presents the Raman bands corresponding to the benzene ring quadrant stretching vibrations $v(C=C)$ at $\sim 1581(\mathrm{~s}) \mathrm{cm}^{-1}$ and $\sim 1625(\mathrm{~ms}) \mathrm{cm}^{-1}$, the band assigned to the carbonyl stretching $v(\mathrm{C}=\mathrm{O})$ at $\sim 1700(\mathrm{~m}) \mathrm{cm}^{-1}$, the band corresponding to the bending 
$\delta(\mathrm{NH}), \delta(\mathrm{CH})$ modes at $\sim 1445(\mathrm{~m}) \mathrm{cm}^{-1}$ and $\sim 1360(\mathrm{~m}) \mathrm{cm}^{-1}$, the stretching $v(\mathrm{C}-\mathrm{N})$ modes at $\sim 1300(\mathrm{~m}) \mathrm{cm}^{-1}$, and a strong band at $\sim 1250(\mathrm{~s}) \mathrm{cm}^{-1}$ corresponding to $\delta(\mathrm{CH}), \delta(\mathrm{C}=\mathrm{O})$ bending modes. In addition, the band proper to the brominated indigoid compounds, corresponding to the stretching modes of the $\mathrm{Br}-\mathrm{C}$ bonds, which for the $6,6^{\prime}-\mathrm{DBI}$ are at the symmetrical positions $6,6^{\prime}$, is strongly resolved at $\sim 305$ (s) $\mathrm{cm}^{-1}$.

The identification of the $6,6^{\prime}$-DBI in the purple pigment through a well-resolved microRaman spectrum answers, satisfactorily in most cases, the primary archaeological question: the recognition of the murex identity of the dye, which automatically ascertains its added value. However, with Raman analysis, it is unlikely to detect any other than the DBI chromophore compound possibly present in the dye.

With the HPLC-DAD analysis, a more accurate determination of all chromophores present in the samples was possible. Three major peaks were detected in the HPLC profiles (Figure 4), which correspond to 6-bromoindigotin (MBI), 6,6'-dibromoindigotin (DBI), and 6,6'-dibromoindirubin (DBIR). Moreover, indigotin (IND), $6^{\prime}$-bromoindirubin (MBIR) and 6-bromoindirubin (MBIR) were detected in the chromatograms but corresponded to very small HPLC peaks, as illustrated in Figure 4 in the chromatogram of sample AKR-10882 shown in higher detail. Finally, indirubin (IR), which is usually found in molluscan extracts in small amounts [46-48], was not detected in any of the examined archaeological samples.

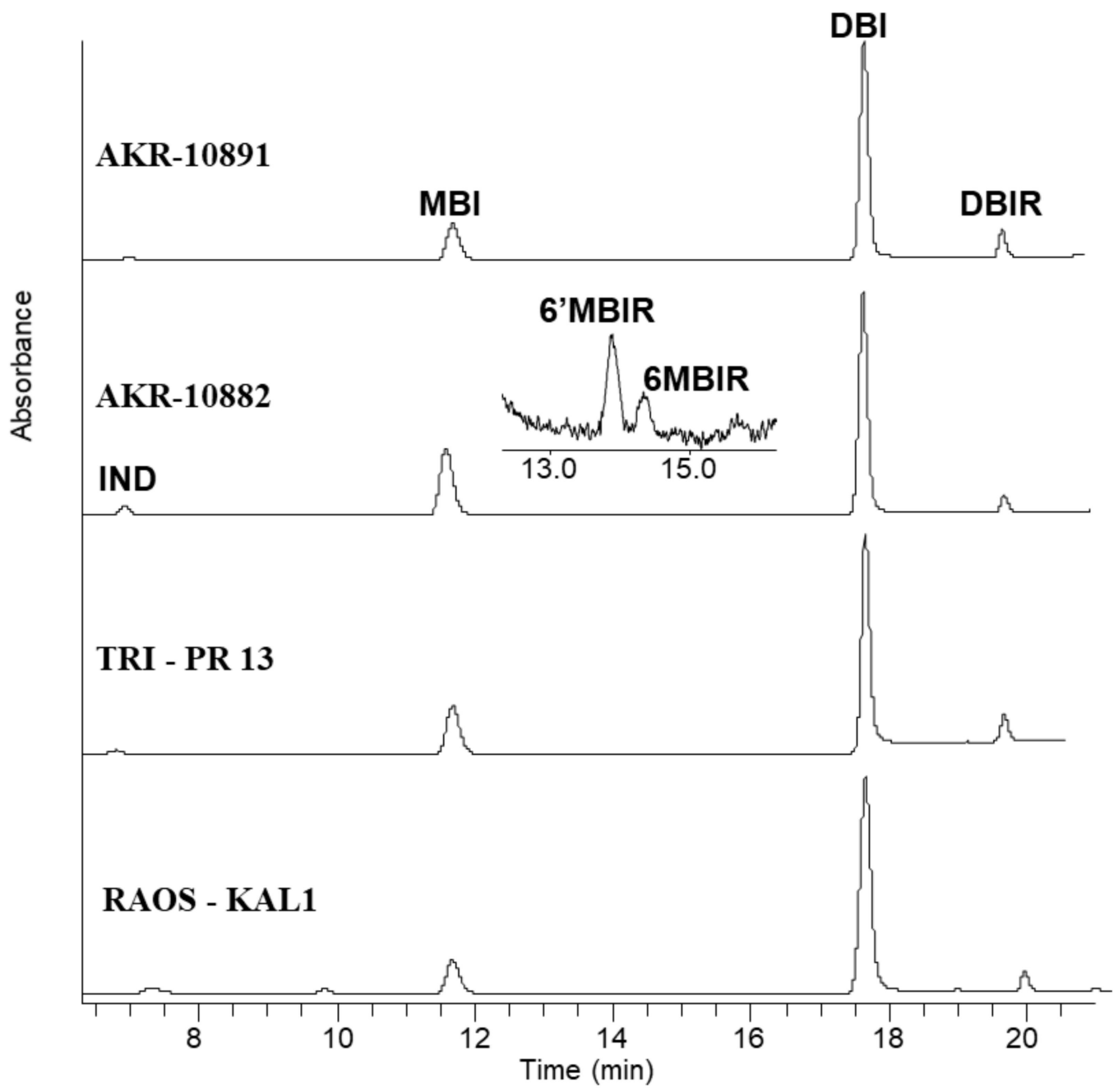

Figure 4. Chromatograms that were collected at $288 \mathrm{~nm}$ for the archaeological samples. The major HPLC peaks correspond to MBI, DBI and DBIR. Much smaller peaks were recorded for IND, 6'MBIR and 6MBIR as revealed for instance in the chromatogram of sample AKR-10882, shown in higher detail. The graphs for the samples AKR-10891 and AKR-10882 were adapted from [30] (with permission from Elsevier) and [32], respectively. 
The aforementioned observations, which are visualized in the HPLC chromatograms, are clearly stated in the relative (\%) values estimated from the integrated HPLC peak areas, as given in Table 1 . The measurements were carried out using a monitoring wavelength of $288 \mathrm{~nm}$ [30]. Apparently, the given numbers are not the actual mass compositions of the samples. Based on the findings of a previous study it was to be expected that the \% of DBI and IND reported in Table 1 would be an underestimation and overestimation, respectively, of the actual relative mass concentrations of the two compounds [48]. However, the semiquantitative results, which are summarized in the table, are a good approximation of the actual concentrations and a very useful approach to compare the samples.

Table 1. Relative (\%) integrated HPLC peak areas measured at $288 \mathrm{~nm}$. The results are provided separately for the major HPLC peaks (MBI, DBI and DBIR) and as a sum for the minor HPLC peaks.

\begin{tabular}{ccccc}
\hline Sample & MBI & DBI & DBIR & IND + 6'MBIR + 6MBIR \\
\hline AKR-10891 & 20.0 & 71.5 & 7.0 & 1.5 \\
AKR-10882 & 26.9 & 65.5 & 3.8 & 3.8 \\
TRI-PR13 & 24.2 & 65.9 & 6.9 & 3.1 \\
RAOS-KAL1 & 15.5 & 77.3 & 5.6 & 1.6 \\
\hline
\end{tabular}

The chromatographic analysis in Figure 4 and Table 1 confirmed the identification of molluscan purple in the four archaeological samples and revealed that the purple pigments and paints have similar compositions. DBI is the dominant compound in the four chromatograms of Figure 4, followed by MBI and DBIR. In the case it was detected, IND corresponded to an extremely small peak. These results suggest that, based on the identified composition of indigoid chromophores, the Late Cycladic purple pigment should have had a pure purple hue, with balanced proportions of red and blue components if not with a tendency to reddish purple. The actual color of the investigated samples, as appeared to the naked eye (see Figures 1 and $2 a$ ) and under microscope (see Figure $2 b$ and Figure 6), as well as the measurements with VIS spectroscopy in the find (inv. no. 10891) [23], confirmed the HPLC-based assumption: There was no predominant bluish tint, which is often observed in molluscan pigments rich in blue IND [49].

As reported in previous published works, in the Mediterranean, there are three mollusc species that were used for dyeing and painting in antiquity: Hexaplex trunculus L. (Murex trunculus), Bolinus brandaris L. (Murex brandaris), and Stramonita haemastoma (Thais haemastoma). Studies on the significant amounts of shells found in several settlements on Crete (Palaikastro, Kouphonisi [5,50,51], Kommos [52], Chryssi, Pefka [53,54]), Kythera, Thera, Greece) and other insular and continental sites in Greece, as well as on the Eastern Mediterranean coasts, all agree on the almost exclusive majority of $M$. trunculus, with the exception of the Kythera case (a small settlement near Kastri), where M. brandaris is attested to be in abundance [55], whereas the incidence of T. haemastoma is always significantly lower.

The extraction of the Bronze Age Aegean purple principally from the M. trunculus as suggested by the archaeomalacological investigations is here supported by the HPLC findings with reference to related chemical studies [30]. These results about the biological source of the purple, although indicating the foremost exploitation of M. trunculus in purple dyeing, do not exclude the scenario of the addition of a regulated proportion of raw material from the $M$. brandaris species in order to obtain a unique, warmer shade of the expensive color.

4.2. Characterization of the Inorganic Substrate and Discussion of the Preparation Method of the Pigment as a Branch in the Operating Chain of the Purple Dyeing Industry

In the microRaman spectra, Figure 3 , the characteristic vibrational band at $1085 \mathrm{~cm}^{-1}$ evidenced the presence of calcium carbonate in the composition of all the examined purple samples, either those from the pigment lumps (AKR-10891, AKR-10882, and TRI-PR 13) or the sample from the Raos wall paintings (RAOS-KAL1). This band, assigned to the $v_{1}$ 
symmetric stretching of $\mathrm{CO}_{3}{ }^{2}$ - in the calcium carbonate molecule, is rather similar for the two calcium carbonate allotropes $\left(\sim 1086.2 \mathrm{~cm}^{-1}\right.$ for pure calcite and $1085.3 \mathrm{~cm}^{-1}$ for pure aragonite) [56]. This slight difference is smaller than the instrument's spectral resolution $\left(\sim 3 \mathrm{~cm}^{-1}\right)$ and therefore could not be used for the distinction of the two polymorphs in the archaeological samples. Given that the resolved band at $152 \mathrm{~cm}^{-1}$ (Figure 3) assigned to lattice vibrational mode is also common for calcite and aragonite, it is customary to focus on other additional, though weak, vibrational bands for the identification of the two allotropes. The most characteristic differences in the Raman spectra of calcite and aragonite are (a) the relative integrated intensities (with respect to the $v_{1}$ band) of the bands at $\sim 283.6 \mathrm{~cm}^{-1}$ for aragonite and $\sim 281.2 \mathrm{~cm}^{-1}$ for calcite (for aragonite the integrated intensity of this band is at least 20 times weaker than the corresponding one of calcite, for which it is the second strongest peak in the spectrum) and (b) a band at $214.7 \mathrm{~cm}^{-1}$ in the aragonite Raman spectrum, which is specific and may as well be used for its identification [56]. If the $1085 \mathrm{~cm}^{-1}$ band in the spectra shown in Figure 3 was assigned to calcite, a corresponding band at $\sim 280 \mathrm{~cm}^{-1}$ (characteristic also for calcite) should have been resolved in the Raman spectra, which was not the case. The latter indirectly suggests aragonite as the calcium carbonate allotrope identified here. Additionally, a weak band resolved at $\sim 210 \mathrm{~cm}^{-1}$, whose intensity increased proportionately to the respective one of $1085 \mathrm{~cm}^{-1}$, agreed with the aforementioned suggestion.

Complementary data were collected with the corresponding FTIR spectra acquired from a few particles of each of the investigated samples. It should be mentioned that the FTIR spectra refer to a higher amount of sample, and thus are more representative of the bulk pigment than the Raman spectra acquired on single particles focused under the $100 \times$ objective of the Raman microscope, which allows a spatial resolution close to $1 \mu \mathrm{m}$. In the FTIR spectra shown in Figure 5a, it is possible to identify with certainty both aragonite and calcite in the inorganic substrate of the pigment based on the bands that are specific to one of the calcium carbonate polymorphs. In the case of the samples taken from wall-painting details, calcite may have derived also from the lime-based ground or may refer to chalk white as a pigment in the painting. However, the identification of both calcium carbonate allotropes and aragonite in particular in the purple pigment found in lump form puts in evidence the marine origin of the calcium carbonate substrate of the organic pigment. In the FTIR spectra, the well-resolved bands at 1475, 1081, 860, 711, and $700 \mathrm{~cm}^{-1}$ perfectly reproduce the respective characteristic bands of pure aragonite. Among the IR absorption bands of the carbonate ion, the split peaks at 711 and $700 \mathrm{~cm}^{-1}$ $\left(v_{4}\right.$ mode) and the peak at $1081 \mathrm{~cm}^{-1}\left(v_{1}\right.$ mode) are specific to the aragonite structure whereas the peak assigned to the $v_{2}$ mode appears with a difference of $\sim 15 \mathrm{~cm}^{-1}$ for the two polymorphs, namely, at $860 \mathrm{~cm}^{-1}$ for aragonite versus $875 \mathrm{~cm}^{-1}$ for calcite $[57,58]$. Additionally, the stronger and broad absorption band assigned to the $v_{3}$ mode, presenting a significant shift for calcite (at $1421 \mathrm{~cm}^{-1}$ ) compared to aragonite (at $1475 \mathrm{~cm}^{-1}$ ), further confirmed the presence of both calcium carbonate polymorphs in the composition of the purple pigments. For the identification of the DBI compound, only the two main bands at 1635 and $1612 \mathrm{~cm}^{-1}$ were barely resolved on the slope of the main broad carbonate band, Figure 5b, [26,43,45].

Examining a sample of the purple pigment from Trianda (TRI-PR13) under microscope, it was possible to observe the aragonite crystals with the characteristic needle-shaped form and clear appearance, as shown in Figure $6[58,59]$. In agreement with the presented FTIR data, in an older study of the purple lump (AKR-10891) with X-ray diffraction analysis [60], magnesium-rich calcite was also identified, which together with aragonite strengthened the assumption that the inorganic base of the pigment was possibly obtained from crushed and ground shells. The "recycling" of shells, of any species, either food residues or debris of purple production (Muricidae family), was a well-known practice not only for obtaining the base of the purple pigment but also for their use as coarse aggregate in the floor mortars or as raw material for the production of lime. 


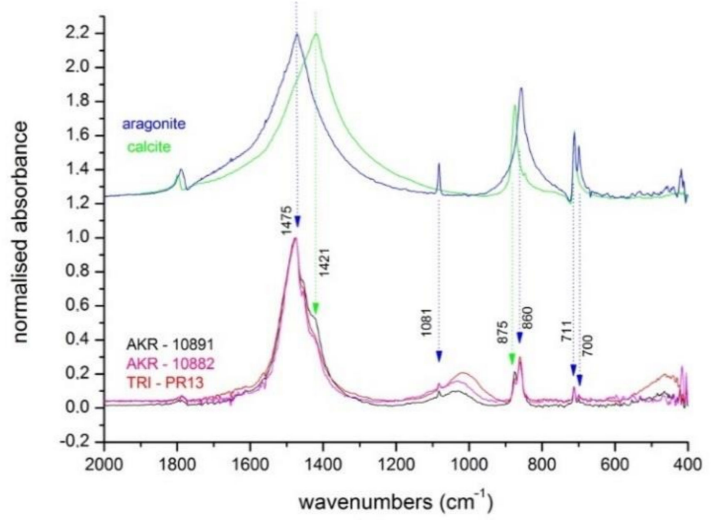

(a)

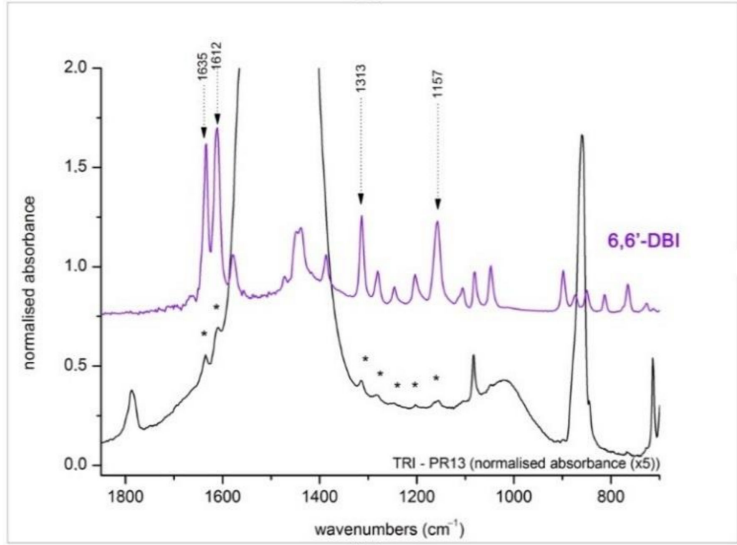

(b)

Figure 5. (a) FTIR spectra acquired in transmission mode on $\mathrm{KBr}$ pellets of samples from the purple pigments (AKR-10882, AKR-10891, and TRI-PR13) found free of any support. Both aragonite and calcite are identified in the inorganic substrate of the pigment. (b) Zoom in on FTIR Scheme 13. The major characteristic vibrational bands of the $6,6^{\prime}$-DBI compound, namely, at 1635, 1612, 1313, and $1157 \mathrm{~cm}^{-1}$, are barely resolved on the slopes of the main broad carbonate band.
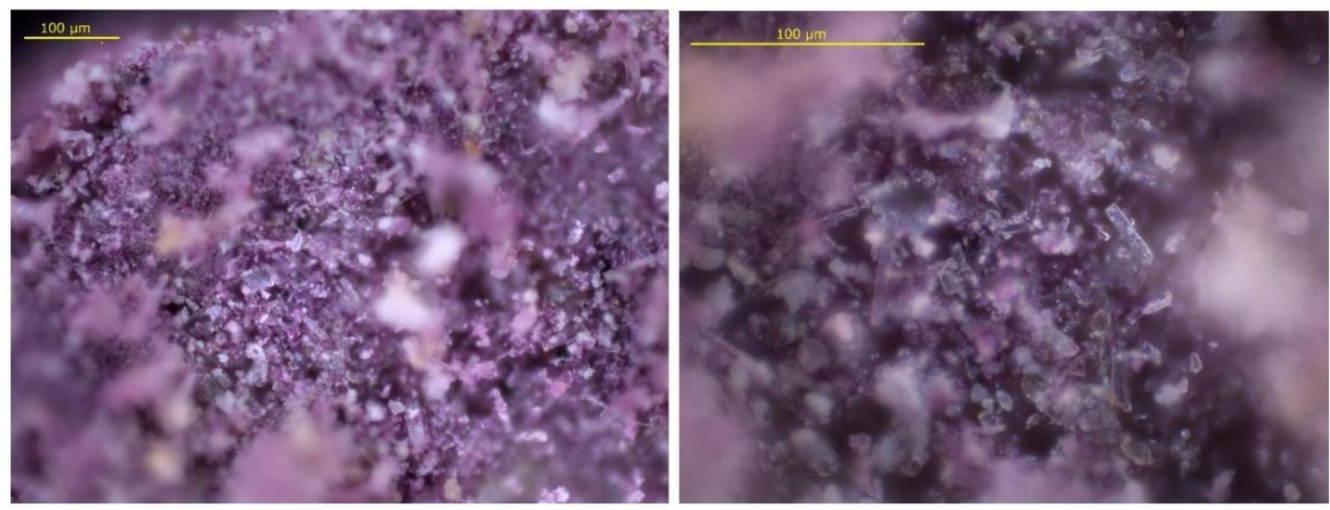

Figure 6. Microphotographs in different magnifications (original magnification $200 \times, 500 \times$ ) of the purple pigment TRI-PR13 from Trianda in white light. The transparent longitudinal crystals of aragonite are evident in the purple matrix in the higher magnification, in particular.

The composition of the purple pigment consisting of a calcium carbonate substrate to which the purple dye was adsorbed, possibly by immersion in the alkaline juice as described by Pliny the Elder [21] in the procedure for preparing the pigment purpurissum, attests to its preparation in a vat, rendering improbable the application of a direct "primitive" 
technique. These data allow the establishment of vat-dyeing know-how to be traced at least back to the Late Bronze Age in the Aegean [23,61,62].

Reviewing the published results of analyses of shellfish purple pigment found in different archaeological contexts over time, in different applications and substrates, it appears that the inorganic base of the pigment can vary [32]. The choice of the inorganic base may have been related not only to the availability of the raw material but may also have been dictated by the substrate to which it was applied. For the wall paintings, the calcitic basis of the purple presents a perfect affinity with the lime-based ground and the calcium white used in a mixture with the rest of the pigments for rendering the light colors. An interesting alternative instance of shellfish purple was identified in the paint decoration of a funerary kliné, in Daskyleion (5th century BCE), with kaolinite being the main constituent of the inorganic base of the organic pigment, applied in that case on a white ground made of gypsum [63]. In the same paper, the HPLC data acquired from samples extracted from the purple paint detail on the kliné were discussed in comparison with the data acquired from an extract from a purple dyed-textile find, found within the same tomb. The perfect match of the HPLC profiles of the two extracts, from the purple pigment and the purple-dyed textile in the same context, constitutes a strong analytical demonstration of the argument suggesting the production of the purple pigment was integrant to the purple dyeing industry of textiles, according to Pliny's text.

Moving even further onward in time, and referring to a shellfish purple pigment identified in the paint decoration of Hellenistic terracotta figurines excavated from a rockcut tomb in Chania, Crete (ca. 300 BC) [64], another white earth, huntite was identified in association with the purple pigment. Although in that case huntite was not directly attributed to the inorganic base of the purple pigment, this should be considered as a possibility. Interestingly, in a more recent investigation [65], huntite was also identified in association with the molluscan purple color revealed among bones and fragments of unidentified materials preserved in a gold larnax of the chamber of Tomb II, in the Macedonian royal tomb complex at Aegeae discovered by Prof. M. Andronikos. These data provide evidence for a wider range of white earth that apparently was known to be appropriate for use in the purple dyeing/pigment preparation operating chain.

\subsection{Indirect Evidence for a Purple Dyeing Industry in the Aegean Sites of Thera and Rhodes}

Although there is strong evidence for relating the purple color in the Theran and Rhodian contexts, with the Late Bronze Age industry of purple dyeing, there are no conclusive data for the location of the dyeing workshops, since there is not yet evidence of such installations in the excavated parts of the settlements. Instead, we present here only a number of strong arguments that support their possible existence outside the excavated sections, which correspond to residential areas.

The significant quantities of seashells found, most of them fragmented, in different buildings and streets at Akrotiri [66], corresponding to the stratigraphic and chronological sequence of the Late Cycladic I period, are considered food refuse, as the probability that dyeing installations existed near an inhabited area is highly unlikely. The largely attested second use of the shells in many instances as construction material for the floors of many rooms (Xeste 3, Pithoi Storeroom A2, B6 inter al.) [67] (pp. 195-196), (Figure 6), [68] (p. 124), as well as in mortar, as a filler in pottery production, etc., could more likely be associated with systematic recycling of waste products from the purple industry, with organized food scrap collection being less likely [66,69] (Figure 4), [70] (pp. 43, 44), (Figures 5 and 6), [5,71,72]. In another context, the evidence for the second use of murex shells, without indication of whether they are remains of foodstuffs or dyes, either in the production of lime plaster or in pieces visible on plastered surfaces probably to strengthen floor beddings, is discussed extensively in [73].

However, the murex finds (mostly M. trunculus), in fact crushed, whether food debris or used as construction material or as a filler in pottery production, etc., dating to the Late 
Cycladic I/Late Minoan IA period, are proof of familiarity with the molluscs, implying the existence of a murex purple-dye industry at Akrotiri [5,72,74].

The lumps of mollusc purple found at Akrotiri together with lumps of other pigments in the same contexts could be intended for painting. The identification of mollusc purple pigment on murals at Akrotiri [22,75] and Raos [42] suggests its most probable application in monumental painting on Thera. The pigment was used selectively on the wall paintings. It was applied on certain petals of the rosettes in the "Rosette and Lily" wall painting from the Raos residential building. It was also used to render the petals of the crocus flowers, a necklace, and many details of the richly adorned female garments, and snoods in the wall paintings of the "Saffron Gatherers," the "Procession of Women with Bouquets," and the "Adorants" from Xeste 3 at Akrotiri [22].

The use of purple in the women's costumes implicitly refers to a possible second (or probably first) application of the purple color on Thera, the dyeing of textiles. In addition, textile production would have been quite a flourishing activity at the site, given the numerous loom weights found there [76-79]. All this evidence from Thera, both scientific (physical and chemical identification) and iconographic, reinforces the view that there was murex purple dye production on the island.

Excavations conducted since 1984 in the prehistoric settlement at Trianda on Rhodes have yielded evidence of a rather frequent use of M. trunculus in the settlement, not only by their sporadic presence along with other finds associated with food consumption, but also by the large quantities of crushed shells used either for reinforcing lime plaster or for constructing a strong substrate for plastered pavements, as in the case of the polythyron in the Markos plot [38]. On the other hand, many pigments, mostly red or pink and in some cases blue or white, were found in lumps or in powder form inside vases, mainly conical cups, or even without containers. Consequently, some of the above pigments might had been used by the painters, itinerant or local, who created the amazing frescoes that decorated the Late Bronze Age IA and even the earlier buildings at Trianda. Most recently, many lumps of pink pigment and pigments of other colors were found in the Middle Bronze Age levels of the settlement. Shiny red plasters decorated the houses of the settlement during this early period [36]. A deposit of thousands of murex shells, found in an open area close to a Middle Bronze Age polythyron, recently revealed during the excavation of the Atsiknoudas plot [80], south of the main Late Bronze Age city, provided further evidence of the early technologies and the activities of the society at Trianda, before the Minoan expansion. Moreover, the presence of many loom weights in an area east/southeast of the main settlement suggests large-scale textile production [36], which might be connected with dyeing as well. However, the only purple production workshop excavated thus far on the island of Rhodes is the Hellenistic installation found in the town of Rhodes, south of the Hellenistic fortification wall [81].

\section{Conclusions}

Lumps of mollusc purple pigment of similar physical appearance have been excavated at the Aegean sites of Akrotiri on Thera and Trianda on Rhodes dating from the Early Late Cycladic period. The same pigment was identified in purple details of certain wall paintings at Akrotiri and Raos, on Thera.

The chemical composition of the purple pigment was identified with molecular spectroscopies, microRaman and FTIR. It consisted of a calcium carbonate substrate to which the shellfish purple dye was adsorbed, possibly by immersion into a dye bath. The calcium carbonate substrate of the pigment, consisting mainly of aragonite and calcite, put in evidence its shell origin and referred to the "recycling" of shells of any species. The HPLC profiles collected from the archaeological samples were all similar, as they contained the same indigoid compounds in a comparatively similar relative content. MBI, DBI, and DBIR were recorded to be in the majority, whereas IND, $6^{\prime} \mathrm{MBIR}$, and $6 \mathrm{MBIR}$ were present in much lower proportions. 
Although there is not yet direct evidence for the location of purple dyeing installations in the Theran or Rhodian Late Bronze Age contexts, there are several arguments presented in this work that allow for the purple color identified in Akrotiri and Raos on Thera as well as in Trianda on Rhodes to be related with the Aegean Late Bronze Age industry of murex purple dyeing. The deposits of murex shells as well as the largely attested second use of the shells in many instances at Akrotiri and Trianda could more likely be associated with the systematic recycling of waste products from the purple industry than with an organized deposition of food debris. In addition, the large-scale textile production suggested by the numerous loom weights found in both sites might be connected with dyeing as well. Finally, the use of the purple pigment analyzed in this paper in several scenes in the Xeste 3 wall paintings at Akrotiri to render with naturalism not only the purple petals of the crocus flowers but also several details in women's woven costumes implicitly reinforces the probability of a local purple textile dyeing industry at the beginning of the Late Bronze Age.

Author Contributions: Conceptualization, S.S.; analytical methodology and investigation, S.S., I.K. and K.S.A.; archaeological context, T.M., K.B. and M.M.; writing-original draft preparation, review and editing, all authors. All authors have read and agreed to the published version of the manuscript.

Funding: This research received no external funding.

Institutional Review Board Statement: Not applicable.

Informed Consent Statement: Not applicable.

Data Availability Statement: Data available on request from the authors.

Acknowledgments: The authors would like to thank Christos Doumas, Director of the Excavations at Akrotiri, Thera, for permission to publish and support in studying the archaeological material from the settlement at Akrotiri. MicroRaman measurements were carried out in the Laboratory of Dynamics, Interactions and Reactivity LADIR, UMR 7075 CNRS/UPMC, Campus CNRS, Thiais. Special thanks are due to Ludovic Berlot-Gurlet for his valuable assistance. The main corpus of analytical data obtained with HPLC and FTIR techniques was produced and elaborated during previous affiliation of the first, second, and third authors to the Ormylia Foundation, Art Diagnosis Centre.

Conflicts of Interest: The authors declare no conflict of interest.

\section{References}

1. Marín-Aguilera, B.; Iacono, F.; Gleba, M. Colouring the mediterranean: Production and consumption of purple-dyed textiles in pre-roman times. J. Mediterr. Archaeol. 2018, 31, 127-154. [CrossRef]

2. Harris, S. From value to desirability: The allure of worldly things. World Archaeol. 2017, 49, 681-699. [CrossRef]

3. Ventris, M.G.F.; Chadwick, J. Documents in Mycenaean Greece, 2nd ed.; Cambridge University Press: Cambridge, UK, 1973 ; p. 573.

4. Reese, D.S. Industrial Exploitation of Murex Shells; Purple-dye and Lime Production at Sidi Khrebish, Benghazi(Berenice). Libyan Stud. 1980, 11, 79-93. [CrossRef]

5. Reese, D.S. Palaikastro Shells and Bronze Age Purple-Dye Production in the Mediterranean Basin. Annu. Br. Sch. Athens 1987, 82, 201-206. [CrossRef]

6. Reese, D.S. Iron age shell purple-dye production in the Aegean. In Kommos IV, The Greek Sanctuary; Part 1; Shaw, J.W., Shaw, M.C., Eds.; Princeton University Press: Princeton, NJ, USA, 2000; pp. 643-645.

7. Reese, D.S. Shells from Sarepta (Lebanon) and East Mediterranean Purple-Dye Production. Mediterr. Archaeol. Archaeom. 2010, 10, $1-31$.

8. Brogan, T.M.; Betancourt, P.P.; Apostolakou, V. The purple dye industry on Eastern Crete. In KOSMOS: Jewellery, Adornment and Textiles in the Aegean Bronze Age; Lafineur, R., Nosch, M.-L., Eds.; Aegaeum 33; Peeters: Lueven-Liège, Belgium, $2012 ;$ pp. 187-193.

9. Carannante, A. Archaeomalacology and purple-dye: State of the art and new prospects of research. In Moluscos y Púrpura en Contextos Arqueológicos Atlántico-Mediterráneos: Nuevos Datos y Reflexiones en Clave de Proceso Histórico; Cantillo, J.J., Bernal, D., Ramos, J., Eds.; Universidad de Cádiz: Cadiz, Spain, 2014; pp. 273-282.

10. Macadam, H.I. Dilmun revisited. Arab. Archaeol. Epigr. 1990, 1, 49-87. [CrossRef]

11. Pfälzner, P. The world of the living and the world of the dead. Ger. Res. 2004, 26, 16-20. [CrossRef]

12. James, M.; Reifarth, N.; Mukherjee, A.; Crump, M.; Gates, P.; Sandor, P.; Robertson, F.; Pfälzner, P.; Evershed, R. High prestige Royal Purple dyed textiles from the Bronze Age royal tomb at Qatna, Syria. Antiquity 2009, 83, 1109-1118. [CrossRef] 
13. Breniquet, C.; Desrosiers, S.; Nowik, W.; Rast-Eicher, A. Les textiles découverts dans les tombes de l'âge du Bronze moyen à Chagar Baza, Syrie. In Chagar Bazar (Syrie) 8. Les Tombes Ordinaires de l'âge du Bronze Ancien et Moyen des Chantiers D, F, H, I (1999-2011); Tunca, O., Baghdo, A., Eds.; Peeters: Leuven-Liège, Belgium, 2018; pp. 11-32.

14. McGovern, P.E.; Michel, R.H. Royal Purple dye: Tracing the chemical origins of the industry. Anal. Chem. 1985, 57, 1514A-1522A.

15. McGovern, P.E.; Michel, R.H. Royal Purple dye: The chemical reconstruction of the ancient Mediterranean industry. Acc. Chem. Res. 1990, 23, 152-158. [CrossRef]

16. McGovern, P.E.; Michel, R.H. Royal Purple Dye: Its Identification by Complementary Physicochemical Techniques. Masca Res. Pap. Sci. Archaeol. 1990, 7, 69-76.

17. Koren, Z.C. Archaeo-chemical analysis of Royal Purple on a Darius I stone jar. Microchim. Acta 2008, 162, 381-392. [CrossRef]

18. Kalaitzaki, A.; Vafiadou, A.; Frony, A.; Reese, D.S.; Drivaliari, A.; Liritzis, I. Po-pu-re: Workshops, use and archaeometric analysis in pre-Roman central eastern Mediterranean. Mediterr. Archaeol. Archaeom. 2017, 17, 103-130. [CrossRef]

19. Apostolakou, S.; Betancourt, P.; Brogan, T.; Mylona, D. Chryssi and Pefka: The production and use of purple dye on Crete in the Middle and Late Bronze Age. In Purpureae Vestes V. Textiles, Basketry and Dyes in the Ancient Mediterranean World; Ortiz, J., Alfaro, C., Turell, L., Martínez, M.J., Eds.; Universitat de València: Valencia, Spain, 2016; pp. 199-208.

20. Koh, A.A.; Betancourt, P.P.; Pareja, M.N.; Brogan, T.M.; Apostolakou, V. Organic residue analysis of pottery from the dye workshop at Alatsomouri-Pefka, Crete. J. Archaeol. Sci. Rep. 2016, 7, 536-538. [CrossRef]

21. Pliny the Elder, The Natural History, XXXV, 26. Available online: http://data.perseus.org/citations/urn:cts:latinLit:phi0978.phi0 01.perseus-eng1:35.26 (accessed on 10 January 2021).

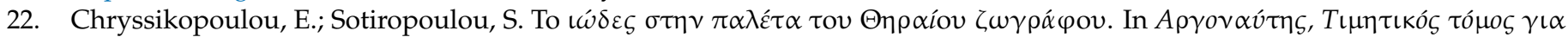

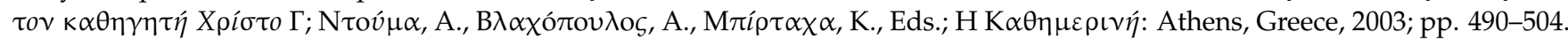

23. Sotiropoulou, S.; Karapanagiotis, I. Conchylian purple investigation in prehistoric wall paintings of the Aegean area. In Indirubin, the Red Shade of Indigo; Meijer, L., Guyard, N., Skaltsounis, A.-L., Eisenbrand, G., Eds.; Life in Progress Editions: Roscoff, France, 2006; pp. 71-78.

24. Karapanagiotis, I.; Sotiropoulou, S.; Chryssikopoulou, E.; Magiatis, P.; Andrikopoulos, K.S.; Chryssoulakis, Y. Investigation of Tyrian purple occurring in prehistoric wall paintings of Thera. In The Diversity of Dyes in History E Archaeology; Kirby, J., Ed.; Archetype Publications: London, UK, 2017; pp. 82-89.

25. Wouters, J. A new method for the analysis of blue and purple dyes in textiles. Dyes Hist. Archaeol. 1992, 10, 17-21.

26. Cooksey, C.J. Tyrian Purple: 6,6'-Dibromoindigo and Related Compounds. Molecules 2001, 6, 736-769. [CrossRef]

27. Meijer, L.; Skaltsounis, A.L.; Magiatis, P.; Polychronopoulos, P.; Knockaert, M.; Leost, M.; Ryan, X.P.; Vonica, C.A.; Brivanlou, A.; Dajani, R.; et al. GSK-3-selective inhibitors derived from Tyrian purple indirubins. Chem. Biol. 2003, 10, 1255-1266. [CrossRef]

28. Meijer, L.; Guyard, N.; Skaltsounis, L.; Eisenbrand, G. (Eds.) Indirubin, the Red Shade of Indigo; Life in Progress Editions: Roscoff, France, 2006.

29. Haubrichs, R. L'etude de la pourpre: Histoire d'une couleur, chimie et experimentations. Preist. Alp. 2005, 40, 133-160.

30. Karapanagiotis, I.; Mantzouris, D.; Cooksey, C.; Mubarak, M.S.; Tsiamyrtzis, P. An improved HPLC method coupled to PCA for the identification of Tyrian Purple in archaeological and historical samples. Microchem. J. 2013, 110, 70-80. [CrossRef]

31. Cooksey, C. Tyrian purple: The first four thousand years. Sci. Prog. 2013, 96, 171-186. [CrossRef]

32. Karapanagiotis, I. A Review on the Archaeological Chemistry of Shellfish Purple. Sustainability 2019, 11, 3595. [CrossRef]

33. Aloupi, E.; Karydas, A.G.; Paradellis, T. Pigment analysis of wall paintings and ceramics from Greece and Cyprus. X-ray Spectrom. 2000, 29, 18-24. [CrossRef]

34. Sotiropoulou, S.; Perdikatsis, V.; Birtacha, K.; Apostolaki, C.; Devetzi, A. Physicochemical characterization and provenance of colouring materials from Akrotiri-Thera in relation to their archaeological context and application. Archaeol. Anthr. Sci. 2012, 4, 263-275. [CrossRef]

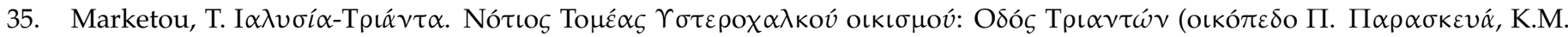
$\left.668^{\mathrm{A}}\right) . A \triangle 1998,53,952-953$.

36. Marketou, T. Ialysos and its neighbouring areas in the MBA and LB I periods: A chance for peace. In The Minoans in the Central, Eastern and Northern Aegean-New Evidence. Acts of a Minoan Seminar 22-23 January 2005 in Collaboration with the Danish Institute at Athens and the German Archaeological Institute at Athens; Macdonald, C.F., Hallager, E., Niemeier, W.-D., Eds.; Monographs of the Danish Institute at Athens: Athens, Greece, 2009; Volume 8, pp. 73-96.

37. Marketou, T. The art of the wall painting at Ialysos on Rhodes: From the early second millennium BC to the Eruption of the Thera

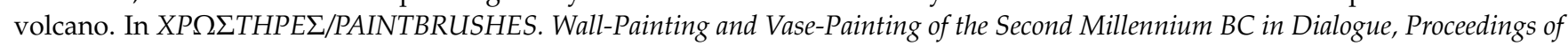
the International Conference on Aegean Iconography, Akrotiri, Thera, Greece, 24-26 May 2013; University of Ioannina/Hellenic Ministry of Culture and Sports-Archaeological Receipts Fund: Athens, Greece, 2018; pp. 261-275.

38. Marketou, T. New evidence on the topography and site history of prehistoric Ialysos. In Archaeology in the Dodecanese; Dietz, S., Papachristodoulou, I., Eds.; National Museum of Denmark Department of Near Eastern and Classical Antiquities: Copenhagen, Denmark, 1988; pp. 27-33.

39. Marketou, T. Santorini tephra from Rhodes and Kos: Some chronological remarks based on the stratigraphy. In Thera and the Aegean World III; Hardy, D., Renfrew, A.C., Eds.; Thera Foundation: London, UK, 1990; Volume 3, pp. 100-119.

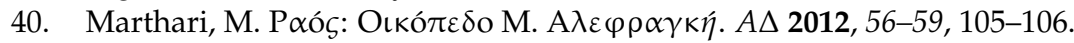


41. Marthari, M. The attraction of the pictorial" reconsidered: Pottery and wall-paintings, and the artistic environment on Late

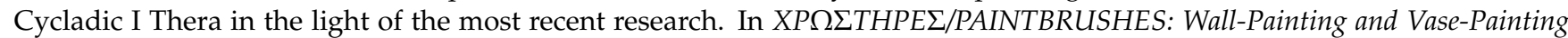
of the Second Millennium BC in Dialogue; Vlachopoulos, A.G., Ed.; University of Ioannina/Hellenic Ministry of Culture and Sports-Archaeological Receipts Fund: Athens, Greece, 2018; pp. 205-221.

42. Marthari, M. Raos and Akrotiri: Memory and identity in LC I/LM IA Thera as reflected in settlement patterns and ceramic production. In MNHMH/MNEME: Past and Memory in the Aegean Bonze Age; Borgna, E., Caloi, I., Carinci, F.M., Laffineur, R., Eds.; Peeters: Leuven-Liège, Belgium, 2019; pp. 135-144.

43. Clark, R.J.H.; Cooksey, C.J. Monobromoindigos: A new general synthesis, the characterization of all four isomers and an investigation into the purple colour of 6,6'-dibromoindigo. New J. Chem. 1999, 23, 323-328. [CrossRef]

44. Karapanayiotis, T.; Villar, S.E.J.; Bowen, R.D.; Edwards, H.G.M. Raman spectroscopic and structural studies of indigo and its four 6,6A-dihalogeno analogues. Analyst 2004, 129, 613-618. [CrossRef]

45. Smith, G.D.; Chen, V.J.; Holden, A.; Keefe, M.H.; Shannon, L.G. Analytical characterization of 5,5'-dibromoindigo and its first discovery in a museum textile. Herit. Sci. 2019, 7, 62. [CrossRef]

46. Karapanagiotis, I.; de Villemereuil, V.; Magiatis, P.; Polychronopoulos, P.; Vougogiannopoulou, K.; Skaltsounis, A.-L. Identification of the Coloring Constituents of Four Natural Indigoid Dyes. J. Liq. Chromatogr. Relat. Technol. 2006, 29, 1491-1502. [CrossRef]

47. Mantzouris, D.; Karapanagiotis, I. Identification of indirubin and monobromoindirubins in Murex Brandaris. Dyes Pigment. 2014, 104, 194-196. [CrossRef]

48. Vasileiadou, A.; Karapanagiotis, I.; Zotou, A. Determination of Tyrian purple by high performance liquid chromatography with diode array detection. J. Chromatogr. A 2016, 1448, 67-72. [CrossRef] [PubMed]

49. Koren, Z.C.; Verhecken-Lammens, C. Microscopic and chromatographic analyses of molluskan purple yarns in a late Roman period textile. E-Preserv. Sci. 2013, 10, 27-34.

50. Bosanquet, R.C. Dicte and the Temples of Dictaean Zeus. Ann. Br. School Athens 1943, 40, 60-77. [CrossRef]

51. Barber, E.J.W. Prehistoric Textiles: The Development of Cloth in the Neolithic and Bronze Age; Princeton University Press: Princeton, NJ, USA, 1991.

52. Ruscillo, D. Faunal remains and murex dye production. In Kommos V: The Monumental Minoan Buildings; Shaw, J.W., Shaw, M.C., Eds.; Princeton University Press: Princeton, NJ, USA, 2006; pp. 776-840.

53. Apostolakou, S. A workshop for dyeing wool at Pefka near Pacheia Ammos. Kentro 2008, 11, 1-2.

54. Apostolakou, V.; Brogan, T.M.; Betancourt, P.P. The minoan settlement on chryssi and its murex industry. In KOSMOS: Jewellery, Adornment and Textiles in the Aegean Bronze Age, Proceedings of the 13th International Aegean Conference, Copenhagen, Denmark, 21-26 April 2010; Nosch, M.L., Laffineur, R., Eds.; Peeters: Lueven-Liège, Belgium, 2012; pp. 179-182.

55. Coldstream, J.N.; Huxley, G.L. Kythera-Excavations and Studies; Faber: London, UK, 1972.

56. De La Pierre, M.; Carteret, C.; Maschio, L.; André, E.; Orlando, R.; Dovesi, R. The Raman spectrum of CaCO 3 polymorphs calcite and aragonite: A combined experimental and computational study. J. Chem. Phys. 2014, 140, 1-12. [CrossRef] [PubMed]

57. Vagenas, N. Quantitative analysis of synthetic calcium carbonate polymorphs using FT-IR spectroscopy. Talanta 2003, 59, 831-836. [CrossRef]

58. Chang, R.; Choi, D.; Kim, M.H.; Park, Y. Tuning Crystal Polymorphisms and Structural Investigation of Precipitated Calcium Carbonates for CO2 Mineralization. ACS Sustain. Chem. Eng. 2017, 5, 1659-1667. [CrossRef]

59. Parker, J.E.; Thompson, S.P.; Lennie, A.R.; Potter, J.; Tang, C.C. A study of the aragonite-calcite transformation using Raman spectroscopy, synchrotron powder diffraction and scanning electron microscopy. Cryst. Eng. Comm. 2010, 12, 1590-1599. [CrossRef]

60. Perdikatsis, V. XRD Analysis Report: Personal communication; School of Mineral Resources Engineering, Technical University of Crete: Chania, Crete, Greece, 2003.

61. Cardon, D. Purple from molluscs. In Natural Dyes; Archetype Publications: London, UK, 2007; Chapter 11; pp. 559-562.

62. Doumet, J. Etude sur la Couleur Pourpre Ancienne et Tentative de Reproduction du Procédé de Teinture de la Ville de Tyr Décrit par Pline l'Ancien; Imprimerie Catholique: Beirut, Lebanon, 1980.

63. Papliaka, Z.E.; Konstanta, A.; Karapanagiotis, I.; Karadag, R.; Akyol, A.A.; Mantzouris, D.; Tsiamyrtzis, P. FTIR imaging and HPLC reveal ancient painting and dyeing techniques of molluskan purple. Archaeol. Anthropol. Sci. 2017, 9, 197-208. [CrossRef]

64. Maravelaki-Kalaitzaki, P.; Kallithrakas-Kontos, N. Pigment and terracotta analyses of Hellenistic figurines in Crete. Anal. Chim. Acta 2003, 497, 209-225. [CrossRef]

65. Maniatis, Y.; Arvaniti, T.; Antikas, T.G.; Wynn-Antikas, L.; Orsini, S.; Ribechini, E.; Colombini, M.P. Investigation of an unusual composite material found in the larnax with cremated bones in royal tomb II at Vergina. In Proceedings of the 40th International Symposium on Archaeometry, Los Angeles, CA, USA, 19-23 May 2014.

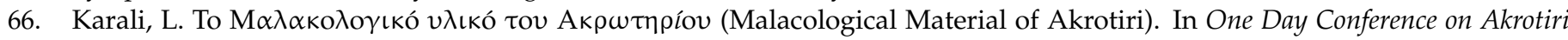

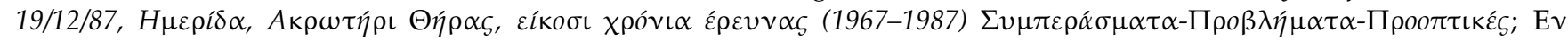

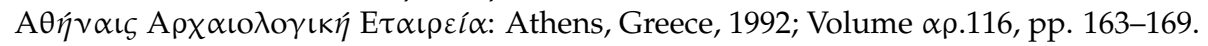

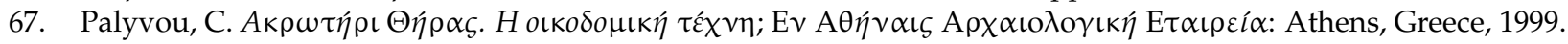

68. Palyvou, C. Akrotiri, Thera: An Architecture of Affluence 3500 Years Old; Prehistory Monographs 15; INSTAP Academic Press: Philadelphia, NJ, USA, 2005. 
69. Karali, L. Sea shells, land snails and other marine remains from Akrotiri. In Thera and the Aegean World III, Proceedings of the Third International Congress, Santorini, (3-9/9/1989); Thera Foundation: London, UK, 1990; pp. 410-415.

70. Karali, L. Shells in Aegean Prehistory; British Archaeological Reports International Series 761; Archaeopress: Oxford, UK, 1999.

71. Doumas, C. Thera: Pompeii of the Ancient Aegean: Excavations at Akrotiri, 1967-1979; Thames and Hudson: London, UK, 1983.

72. Doumas, C. The excavations at Thera and the Aegean late bronze age. Endeavour 1983, 7, 144-149. [CrossRef]

73. Brysbaert, A. Murex uses in plaster features in the Aegean and eastern Mediterranean Bronze age. Mediterr. Archaeol. Archaeom. 2007, 7, 29-51.

74. Aloupi, E.; Maniatis, I.; Paradellis, T.; Karali, L. Analysis analysis of a purple material found at Akrotiri. In Thera and the Aegean World III, Proceedings of the Third International Congress, Santorini, Greece, 3-9 September 1989; Hardy, D.A., Doumas, C.G., Sakellarakis, J.A., Warren, P.M., Eds.; The Thera Foundation: London, UK, 1990; Volume 1, pp. 488-490. [CrossRef]

75. Chrysikopoulou, E. Use of murex purple in the Wall-paintings at Akrotiri, Thera. $A \Lambda \Sigma 2005,3,77-80$.

76. Tzachili, I. All important yet elusive: Looking for evidence of cloth-making at Akrotiri, in 1990. In Thera and the Aegean World III, Proceedings of the Third International Congress, Santorini, Greece, 3-9 September 1989; Hardy, D.A., Doumas, C.G., Sakellarakis, J.A., Warren, P.M., Eds.; The Thera Foundation: London, UK, 1990; Volume 1, pp. 380-389.

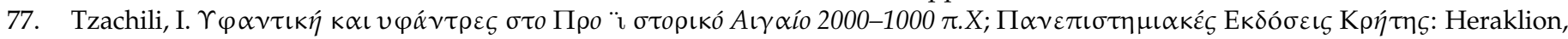
Greece, 1997.

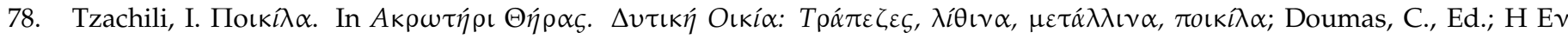

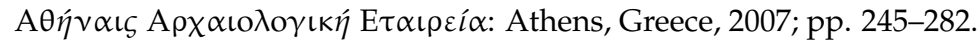

79. Michaelidou, A. Weight and Value in Pre-Coinage Societies, vol. II, Sidelights on Measurement from the Aegean and the Orient; $\mathrm{M \varepsilon} \lambda \varepsilon \tau \tilde{\eta} \mu \alpha \tau \alpha$ 61; Research Centre for Greek and Roman Antiquity, National Hellenic Research Foundation: Athens, Greece, 2008.

80. Marketou, T. Time and space in the middle bronze age aegean world: Lalysos (Rhodes) a gateway to the eastern Mediterranean. In Space and Time in Mediterranean Prehistory; Souvatzi, S., Hadjii, A., Eds.; Routledge: London, UK; Taylor and Francis Group: New York, NY, USA, 2014; pp. 176-195.

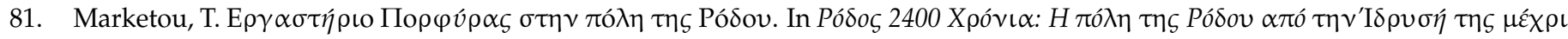

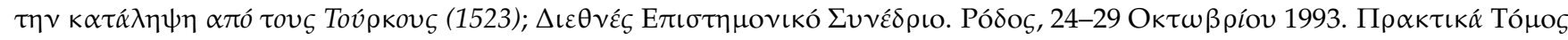

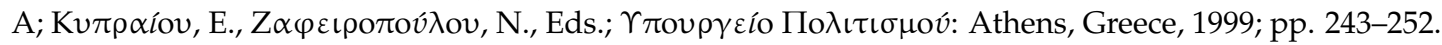

